\title{
Study of the Nickel-Tungsten and Nickel-Cobalt Coatings Plated on Ductile Iron
}

\author{
A. Ayday ${ }^{a, *}$ AND H. SKULEV ${ }^{b}$ \\ ${ }^{a}$ Sakarya University, Faculty of Engineering, Department of Metallurgical and Materials Engineering, \\ Sakarya, 54187, Turkey \\ ${ }^{b}$ Technical University of Varna, 1. Studentska Str., 9010 Varna, Bulgaria
}

\begin{abstract}
Hard coatings such as nickel, chromium and tungsten can improve the surface properties of the substrate. The coating surfaces have been developed for increase of the wear resistance, hardness or corrosion resistance for industrial applications. Electroplating methods generally used to obtain producing these hard coatings and a novel brush plating process has the potential as an alternative of electroplating for industrial applications. In the present work, nickel-tungsten and nickel-cobalt alloys are coated on ductile iron by brush plating for surface characterization. Scanning electron microscopy and energy dispersive spectrometry were used to investigate the coating microstructures, surface morphology. The hardness of plating layers was measured. The results indicated that the nickel-tungsten coating was harder than nickel-cobalt coating. Excellent adhesion was obtained after nickel-cobalt plating. The tribological resistances were also significantly improved, as confirmed by the decrease friction coefficient and wear rate.
\end{abstract}

DOI: 10.12693 /APhysPolA.129.455

PACS/topics: 81.05.Bx, 81.40.Pq, 81.65.Lp

\section{Introduction}

Brush plating is a portable process for accurately applying plated deposits and anodized coatings onto localized areas [1,2]. Brush plating, also known as selective plating or swab plating, is a very useful and portable method of contact plating. In its simplest form, the brush plating process resembles painting. Brush plating equipment includes power packs, solutions, plating tools, anode covers and auxiliary equipment. The power pack has two leads. One is connected to the plating tool and the other is connected to the workpiece to be plated. The anode is covered with an absorbent material which holds the solution. The operator dips the plating tool in the solution and then brushes it against the surface of the workpiece that is to be finished. When the anode touches the work surface a circuit is formed and an electrodeposit is produced. It offers portability, flexibility and high-quality deposits and coatings $[2-4]$. The schematic diagram of brush plating system is shown in Fig. 1. The brush is typically a stainless steel or conducting rod, wrapped with a cloth material. The brush has to be connected to a positive terminal of DC voltage and the negative terminal is connected to substrate. The wrapped cloth holds the plating solution and also prevents direct contact with substrate. At the start, the brush has to dip in the coating solution and then by moving the brush continuously on the substrate with a slow rate of movement the desired layer can be obtained $[5,6]$.

The brush plating technique, different from conventional plating, is an electrochemical process conducted

*corresponding author; e-mail: aayday@sakarya.edu.tr

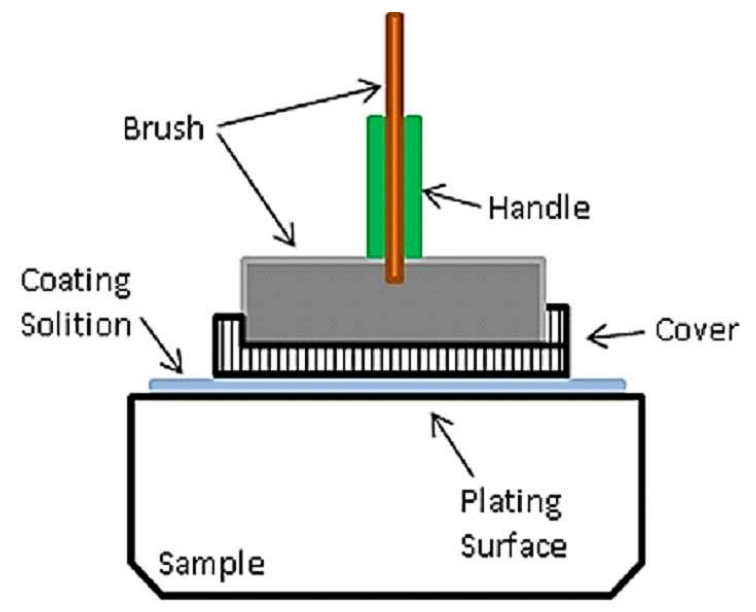

Fig. 1. Schematic diagram of brush plating system.

with an electrolyte applied to the substrate by a socalled brush to form the adherent deposit. Most metals used in conventional electrodeposition can be brush plated; the main applications are for repair and maintenance $[4,7,8]$. In this present work, the nickel-tungsten and nickel-cobalt films are used as the over coat of ductile iron. The surface morphology, microstructure, microhardness, wear resistance of these two coatings were investigated comparatively.

\section{Experimental procedure}

A SIFCO Flow System was used for brush plating the nickel-tungsten and nickel-cobalt alloys. Firstly, the ductile iron substrate was polished and rinsed with deionized water, degreased in ethanol and dried. The brush plating 
was leaded in the following steps: electrical cleaning $\rightarrow$ washing $\rightarrow$ activation $\rightarrow$ plating of nickel-tungsten alloy/plating of nickel-cobalt alloy. After the coating, the samples rinsed with deionized water. The main parameters are shown in Table I.

\section{TABLE I}

Brush plating process of $\mathrm{Ni}-\mathrm{W}$ alloy and $\mathrm{Ni}-\mathrm{Co}$ alloy.

\begin{tabular}{c|c|c|c|c|c}
\hline \hline Step & Operation & Solution & $\mathrm{pH}$ & Polarity & $\begin{array}{c}\text { Voltage } \\
{[\mathrm{V}]}\end{array}$ \\
\hline 1 & electrocleaning & cleaning solution & & positive & 8 \\
2 & washing & - & - & - & - \\
3 & activation & activation solution & & positive & 12 \\
$4(\mathrm{i})$ & plating & Ni/W plating solution & & positive & 10 \\
4 (ii) & plating & Ni/Co plating solution & & positive & 15
\end{tabular}

Morphology and microstructure of the coatings were carried out on the OLYMPUS BHM-313 optical microscope and JEOL, JSM 6060-LU scanning electron microscope (SEM). The surfaces were determined by energy dispersive spectroscopy (EDS) attached to the scanning electron microscope. The Vickers hardness of brush plated coatings by electro-brush plating was measured through a Future Tech-Corp.FM-700 with 100 g load for $8 \mathrm{~s}$. Wear tests were performed on untreated ductile iron and brush plated specimens to determine the wear resistance. All wear tests were carried out under dry sliding conditions at ambient temperature using a reciprocating ball-on-disc friction and wear test machine. Tests were performed with nominal loads of $1-3-5 \mathrm{~N}$ and a sliding speed of $0.15 \mathrm{~m} / \mathrm{s}$ for a total sliding distance of $200 \mathrm{~m}$. After the wear tests, width of wear scars were examined by SEM and calculated the wear rate by the program of CSM tribometer to examine whether any change in wear behavior occurred as a result of the applied surface treatment.

\section{Results and discussions}

The nickel-tungsten and nickel-cobalt films obtained on ductile iron showed smooth adherent surface in Fig. 2a,b. For the brush plating voltage value of $10 \mathrm{~V}$, the obtained $\mathrm{Ni}-\mathrm{W}$ film was about $9.33 \mu \mathrm{m}$ and the voltage value of $15 \mathrm{~V}$ for $\mathrm{Ni}-\mathrm{Co}$ film was about $28.3 \mu \mathrm{m}$ thickness. Figure 3a,b shows cross-section surface morphology of the coatings under SEM. Both of the coatings are continuous and dense.
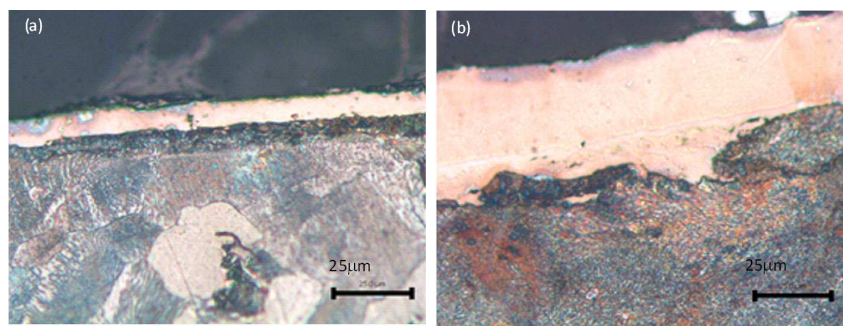

Fig. 2. Optical microscope photograph of brush plated (a) $\mathrm{Ni}-\mathrm{W}$ alloy, (b) Ni-Co alloy.

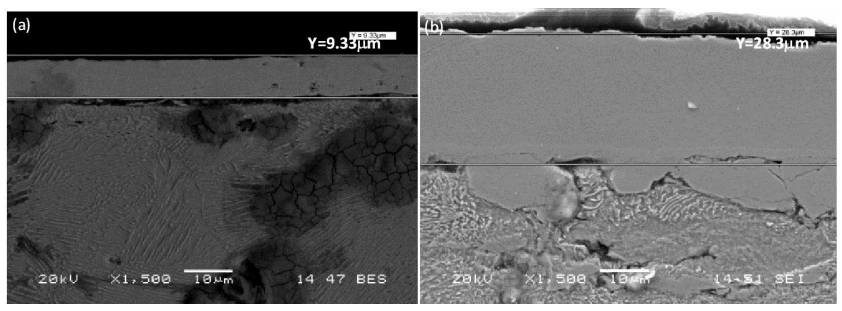

Fig. 3. SEM images of brush plated (a) Ni-W alloy, (b) $\mathrm{Ni}-\mathrm{Co}$ alloy.

Figure 4a,b shows cross-sectional SEM image and composition of the brush plated $\mathrm{Ni}-\mathrm{W}$ and $\mathrm{Ni}-\mathrm{Co}$ alloys measured with EDS maps, respectively. The coating contained $\mathrm{Ni}-\mathrm{W}$ and $\mathrm{Ni}-\mathrm{Co}$ elements on the surface. Mainly $\mathrm{Ni}$ and homogeneously dispersed in small amounts $\mathrm{W}$ were detected in plated $\mathrm{Ni}-\mathrm{W}$ film, and the Fe comes from the specimen (Fig. 4a). For Ni-Co plating sample, Co was the main elements, Co content decreased regularly from outer to inner layers of the coating and very thin $\mathrm{Ni}$ layer was detected from the boundary ductile iron matrix. The Fe comes from the substrate surface (Fig. 4b).

The ductile iron substrate microhardness was $170 \mathrm{HV}_{0.05}$. After brush plating, the coating microhardness was $604 \pm 5 \mathrm{HV}_{0.05}$ for $\mathrm{Ni}-\mathrm{W}$ alloy and $547 \pm 5 \mathrm{HV}_{0.05}$ for $\mathrm{Ni}-\mathrm{Co}$ alloy. The microhardness was mainly dependent on the structure and phase composition. The electric brush plating $\mathrm{Ni}-\mathrm{W}$ layer on the ductile iron led to an increase in the surface hardness nearly 4 times.

Figure 5a,b shows the wear coefficients and wear rates for the untreated ductile iron, brush plated $\mathrm{Ni}-\mathrm{W}$ alloy, brush plated Ni-Co alloy under 1-3-5 N load and at sliding speed of $0.15 \mathrm{~m} / \mathrm{s}$. It can be seen that hard plating also causes change in the contact conditions confirmed by the coefficient of friction (COF). It can be seen that brush plating causes reduction in wear coefficients compared to untreated specimen. The wear resistance for plated $\mathrm{Ni}-\mathrm{W}$ alloy was much higher than that of the plated $\mathrm{Ni}-\mathrm{Co}$ alloy and untreated samples, as shown in Fig. 5b. The microhardness values of the modified samples indicate that plating has the potential to offer good wear resistance to the ductile iron by increasing their hardness. For both brush-plated $\mathrm{Ni}-\mathrm{W}$ and $\mathrm{Ni}-\mathrm{Co}$ alloy layers, the wear rate increased with increasing load.

Figure 6a1-a3 shows the worn surface morphologies of the untreated ductile iron, plated $\mathrm{Ni}-\mathrm{W}$ alloy and $\mathrm{Ni}-$ Co alloy under $1 \mathrm{~N}$ and Fig. 6b1-b3 shows the untreated ductile iron, plated $\mathrm{Ni}-\mathrm{W}$ alloy and $\mathrm{Ni}-\mathrm{Co}$ alloy under $5 \mathrm{~N}$ wear loads, respectively. Figure 6a1 and Fig. 6b1 show that the surface of ductile iron without coating has wide grooves and straight scratches. Brush plated samples show that the surface of coating has clear grooves which become relatively narrow when the hardness increases, there exist regular scratches on the grooves along the friction movement direction (Fig. 6a2,a3,b2,b3) and 
some microcracks were formed with increasing the wear load to $5 \mathrm{~N}$ (Fig. 6b2,b3). Hard coating provides high hardness, excellent wear along with a low coefficient of friction $[6,9]$.

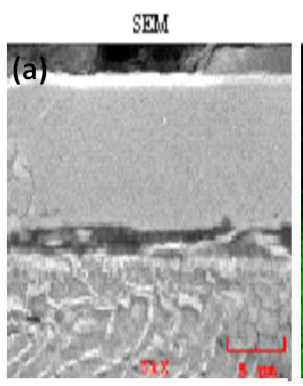

SEMU

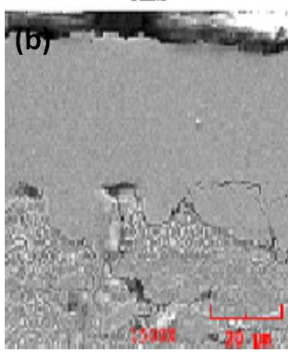

$\mathrm{Fe}$

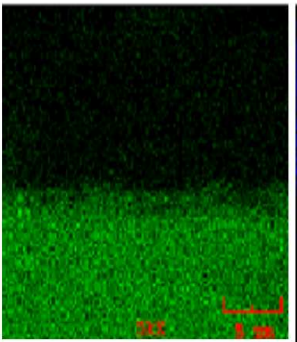

$\mathrm{Fe}$

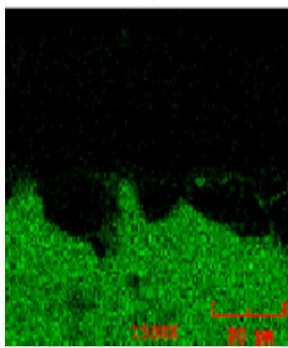

$\mathrm{Ni}$

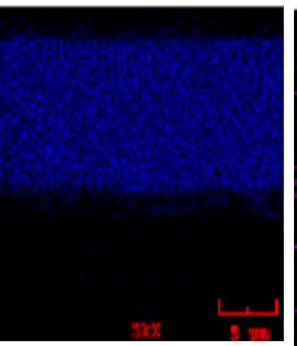

$\mathrm{Ni}$

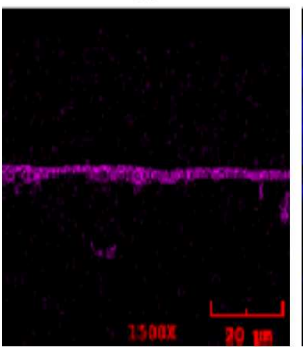

w
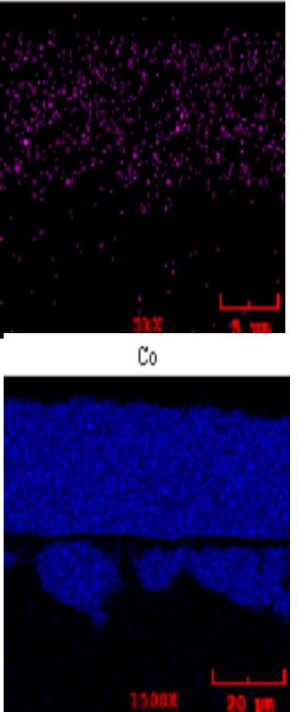

Fig. 4. (a) SEM image of the cross-section and EDS map analysis of brush plated Ni-W alloy; (b) SEM image of the cross-section and EDS map analysis of brush plated Ni-Co alloy.
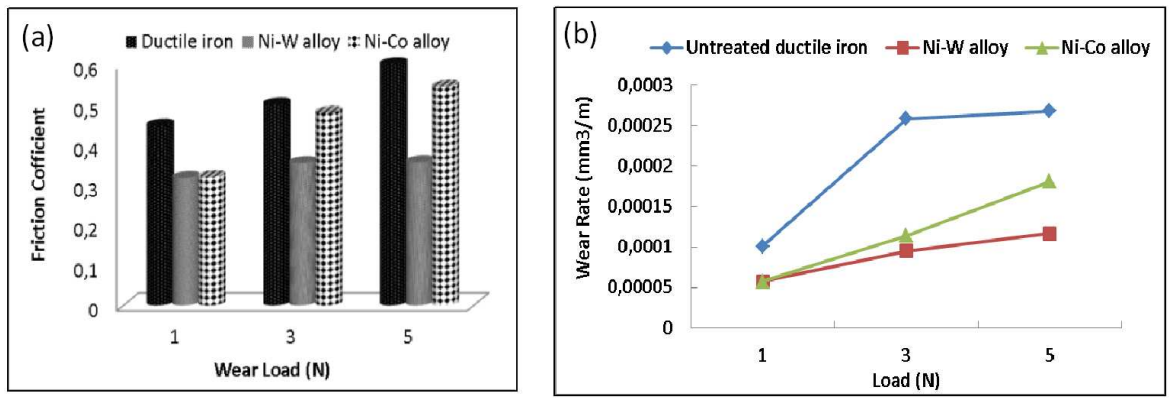

Fig. 5. (a) $\mathrm{COF}$ of the untreated ductile iron, $\mathrm{Ni}-\mathrm{W}$ alloy, $\mathrm{Ni}-\mathrm{Co}$ alloy, (b) wear rates of the untreated ductile iron, $\mathrm{Ni}-\mathrm{W}$ alloy, $\mathrm{Ni}-\mathrm{Co}$ alloy.
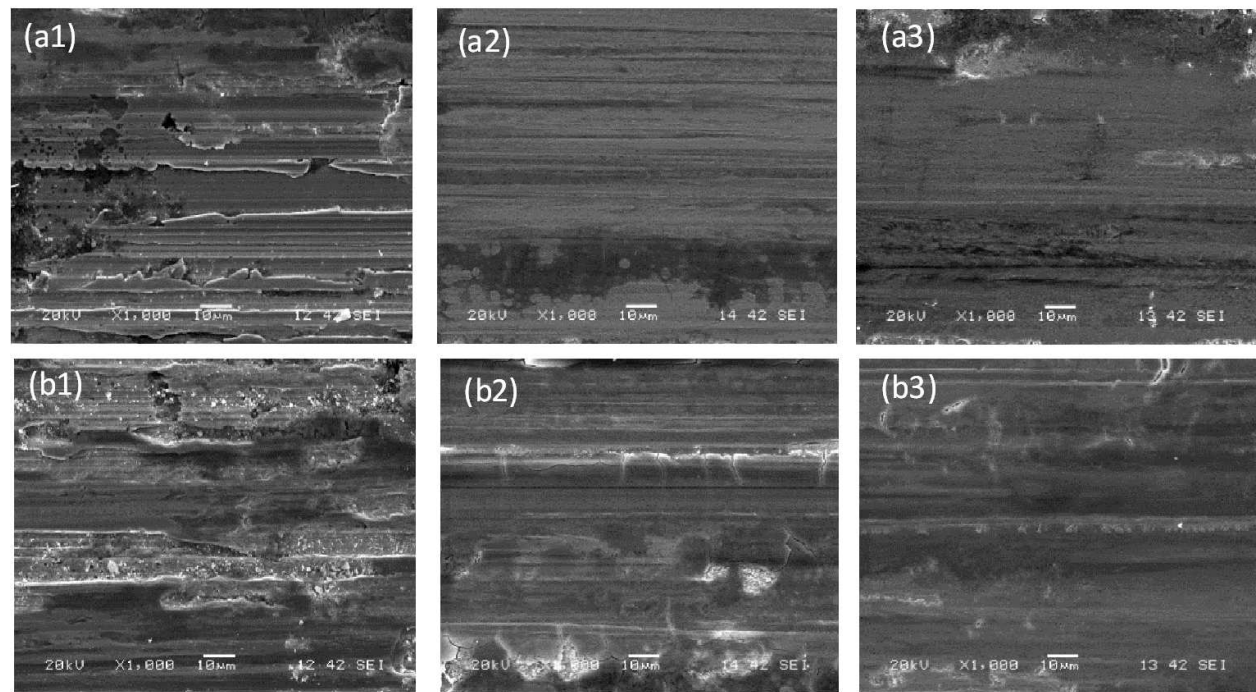

Fig. 6. SEM micrographs showing the worn surface morphologies of (a1,a2,a3) untreated ductile iron, Ni-W alloy, $\mathrm{Ni}-\mathrm{Co}$ alloy under $1 \mathrm{~N}$, (b1,b2,b3) untreated ductile iron, $\mathrm{Ni}-\mathrm{W}$ alloy, $\mathrm{Ni}-\mathrm{Co}$ alloy under $5 \mathrm{~N}$. 


\section{Conclusion}

$\mathrm{Ni}-\mathrm{W}$ alloy and $\mathrm{Ni}-\mathrm{Co}$ alloy coatings are prepared on ductile iron by brush plating. The coatings are uniform and compact, with denser and lower porosity. The coating thickness of $\mathrm{Ni}-\mathrm{Co}$ coating is higher than of $\mathrm{Ni}-\mathrm{W}$ alloy and microhardness of brush platings increases the surface hardness nearly 4 times. Maximum hardness is $604 \pm 5 \mathrm{HV}_{0.05}$ for $\mathrm{Ni}-\mathrm{W}$ coating. The brush plated samples improved the wear resistance of the ductile iron. $\mathrm{Ni}-\mathrm{W}$ plating exhibits higher microhardness, less friction and better wear resistance than $\mathrm{Ni}-\mathrm{Co}$ plating.

\section{Acknowledgments}

The authors would like to thank the Technical University of Varna, Bulgaria and Sakarya University, Turkey for their great technique support.

\section{References}

[1] B. Subramanian, S. Mohan, S. Jayakrishnan, Surf. Coat. Technol. 201, 1145 (2006).

[2] D.A. Molloy, S. Malinov, T. McNally, P. Hill, Prog. Organic Coat. 70, 330 (2011).

[3] Y. Qian, J. Tan, Q. Liu, H. Yu, R. Xing, H. Yang, Surf. Coat. Technol. 205, 3909 (2011).

[4] B. Wu, B. Xu, B. Zhang, Y. Lü, Surf. Coat. Technol. 201, 6933 (2007).

[5] N.K. Reddy, M. Devika, E.S.R. Gopal, Crit. Rev. Solid State Mater. Sci. 40, 359 (2015).

[6] Z. Aydın, G. Aldıç, H. Çimenoğlu, Arch. Mater. Sci. Eng. 65, 87 (2014).

[7] D. Vanek, Metal Finishing 108/9, 25 (2010).

[8] B. Wu, X. Yu, B. Zhang, B. Xu, Surf. Coat. Technol. 202, 1975 (2008).

[9] X. Xie, L. Zhang, J. Xiao, Z. Qian, T. Zhang, K. Zhou, Trans. Nonferrous Met. Soc. China 25, 3029 (2015) 